\title{
Prevalence of Ophthalmological and Dermatological Problems Related to Pesticide Exposure among Sugarcane Farm Workers in Western Maharashtra
}

\author{
Kshitija Dattatray More ${ }^{1}$, Ankita Ramchandra Mane², Sandeep Babasaheb Shinde ${ }^{3}$ \\ 1, 2, 3 Department of Musculoskeletal Sciences, Krishna College of Physiotherapy, Krishna Institute of \\ Medical Sciences Deemed to Be University, Karad, Maharashtra, India.
}

\section{ABSTRACT}

\section{BACKGROUND}

Insecticides, herbicides, etc. are frequently used to improve yields and its overuse and improper use affects the respiratory, cardiovascular systems as well as the eyes and skin of farmers (that is ophthalmological and dermatological systems). Thus, there is need to analyse the prevalence of ophthalmological and dermatological problems related to pesticide exposure among sugarcane farmers in western Maharashtra, which will help to provide advices for education and prevention. The purpose of this study was to analyze and find out the prevalence of ophthalmological and dermatological problems related to pesticide exposure among sugarcane farm workers in western Maharashtra.

\section{METHODS}

This study was an observational studywhich was carried out in southern zone of western Maharashtra. Depending on the basis of inclusion, (males 35 - 45 years old, Exposure more than 5 years.) and exclusion criteria (females, farmers with hypertension and any other metabolic diseases.) 79 farmers (sample size) were selected. Study duration was six months and it was conducted from July 2020 to December 2020. Written consent was taken from them. Participants were selected by random sampling method from 19 villages of western Maharashtra and their detailed outcome assessment was done by using dermatological assessment (assessment of skin) and ophthalmological assessment (assessment of eyes) protocol.

\section{RESULTS}

The obtained results had shown significant problems in both ophthalmological and dermatological systems. Ophthalmological problems are irritation in eyes [51 $(64.55 \%)]$ in subjects of the sample size [79 (100\%)], burning sensation [48 (60.7 $\%)]$, itching [43 (54.4\%)], blurring of vision [17 (21.5\%)], watering of eyes [35 $(44.3 \%)]$, cataract [2 (2.53\%)] and conjunctivitis [10 (12.65\%)]. Out of above problems, irritation in eyes, burning sensation and itching were the most common problems. Dermatological problems are contact dermatitis [(29 (36.70 \%)], urticaria [13 (16.4\%)], ashy dermatosis [5 (6.32\%)], itching [46 (58.22\%)], hypopigmentation [1 (1.26\%)], nail dystrophy [0 (0 \%)], skin cancer [0 (0\%)] erythema multiforme [9 (11.39\%)] and people are found to be dehydrated [51 $(64.55 \%)]$. Out of above problems, itching (46 subjects) and dehydrated skin (51 subjects) were the most common problems.

\section{CONCLUSIONS}

It was concluded that a large number of pesticide exposed sugarcane farmers were exposed to various impairments with different levels of vulnerability. Both, ophthalmological and dermatological systems are vulnerable. Prevalence of ophthalmological and dermatological problems were $37.2 \%$ and $21.6 \%$ respectively.

\section{KEY WORDS}

Pesticides, Insecticides, Contact Dermatitis, Porphyria Cutanea Tarda, Urticaria, Cataract, Conjunctivitis, Blurring of Vision
Corresponding Author: Dr. Sandeep Babasaheb Shinde, Department of Musculoskeletal Sciences Faculty of Physiotherapy, Krishna Institute of Medical Sciences Deemed to Be University, Karad, Maharashtra, India. E-mail: Drsandeepshinde24@gmail.com

\section{DOI: $10.14260 /$ jemds/2021/526}

How to Cite This Article:

More KD, Mane AR, Shinde SB. Prevalence of ophthalmological and dermatological problems related to pesticide exposure among sugarcane farm workers in Western Maharashtra. J Evolution Med Dent Sci 2021;10(32):2565-2569, DOI: $10.14260 / \mathrm{jemds} / 2021 / 526$

Submission 17-03-2021,

Peer Review 09-06-2021,

Acceptance 16-06-2021,

Published 09-08-2021.

Copyright (C) 2021 Kshitija Dattatray More et al. This is an open access article distributed under Creative Commons Attribution License [Attribution 4.0 International (CC BY 4.0)] 


\section{BACKGROUND}

Most of the population in India is living in villages, and most of the people are depending on agriculture as their occupation.1,2 Over last few years, farming practices in India have been modernised and people have started using chemical fertilizers and pesticides for better production.2,3 Many of them do not know the proper use and handling techniques of pesticides, so that it affects their health.1,4 According to world health organization (WHO), pesticides are chemical compounds that are used to kill pests including insects, rodents, fungi and unwanted plants (weeds). There are 1000 different types of pesticides used around the world. ${ }^{2}$ It comprises insect killer (insecticides), weed killers (herbicides), rodent killers (rodenticides), nematicides, molluscicides, plant growth regulators, and many more.3,5 In the following paragraphs, we will look at the deleterious effects of pesticides on the health of farmers, especially the effects of pesticides sprayed on sugarcane.

Western Maharashtra is a leading zone in the field of agriculture. Sugarcane is known as one of the cash crops in western Maharashtra. Sugarcane farmers are at higher risk of health problems due to excessive use of pesticides and less education of use of protective equipment's such as gloves, masks, appropriate clothing etc. ${ }^{2,4}$ Such an improper use of pesticides may have harmful effects on health of sugarcane farmers. It may affect various systems of the body (central nervous systems, gastrointestinal, cardiovascular also the ophthalmic and dermatological symptoms).1,2 Variety of symptoms are found in the sugarcane farmers shown in various studies. Skin irritation, eye irritation, fatigue and headache are the most common problems found in some studies. $^{6}$ Severe neurological problems are caused due to some chemicals such as carbamates, organophosphate etc., because they directly target the nervous system as their mechanism of toxicity. Dizziness, nausea, vomiting, blurred vision, and muscular weakness are some of the acute cholinergic symptoms due to inhibition of cholinesterase during neurotransmission. ${ }^{7}$

Ophthalmological problems are a part of medical area which is concerned with the eye, its problems and refractive errors. Refractive error is common eye disorder. Dermatological problem is part of special medicine which concentrates on conditions that affect the skin. It also includes problems on your hair, eye, nails, eyelids, nose and mouth. In general population, non-occupational accidental events can occur due to exposure of pesticides. According to data, $99 \%$ of affected people have ocular irritation because of higher concentration of pesticidal exposure in environment. ${ }^{8}$

Dermal contact, inhalation and ingestion are the most common routes for pesticide consumption and least common route is ocular.4,9,10 The frequently known effects of pesticide exposure on eyes are irritation, burning sensation, itchiness, blurring of vision, and watering of eyes.11,12-15 Systemic exposure by dermal contact or ingestion of organophosphates causes symptoms such as blurring of vision, burning sensation.9,10,16 Long-term ocular exposure to pesticides may produce chronic effects on the eyes. Beyond the description of the symptoms of eyes, there is toxic effect of pesticides on various components of the eye. These include, effects on the conjunctiva, cornea, iris, lens, retina, and the optic nerve, including visual neural pathways extending from the brain.

Consistent pesticidal exposure can commonly cause nontoxic diseases such as dermatoses, 3,17 as skin is the major organ exposed to pesticide while spraying on the field. The not uncommon clinical form of pesticide related skin diseases is contact dermatitis, both allergic $18,19,20,21,22$ or irritant. 20,23 The less common diseases include contact urticaria, erythema multiforme, ashy dermatoses, occupational acne, porphyria cutanea tarda, hair and nail disorders and skin disorder and some are explained below,

- Contact dermatitis - Pesticides related contact dermatitis - Described by Mc.Cord and Kilkee in $1921 .^{24}$ The skin sensitivity to light has the capacity to increase due to some pesticide components causing phototoxic reactions, ${ }^{25}$ or may undergo photoactivated chemical reaction which produces a derivative allergising to the skin (photo allergy). ${ }^{26}$

- Urticaria - It is a localised vascular oedema in upper dermis which is represented by transient vascular reactions that is caused by dilatation and increased permeability of the capillaries following exposure to the eliciting agent. Wheals are the clinical representation.

- Erythema multiforme - A sudden onset of an erythematous eruption which has characteristic lesions called iris, bull's eye or target lesions, which consist of papules with two or more concentric rings of slightly differing colours.

- Ashy dermatosis - Also known as erythema dyschromicum perstans, is a skin disease significantly occurring in dark-skinned individuals, characterised by the presence of single or multiple ashen macules of variable size and shape. The cause of the disease is unknown.

- Nail dystrophy - It has features like discoloration, deformities, and eventually loss of the nails.

- Hypopigmentation of the skin - Decreased production of melanin (natural skin dye) by melanocytes causes abnormally diminished coloration of skin.

- Porphyria cutanea tarda - This is the most known form of porphyria, featured by cutaneous photosensitivity that causes scarring bullae, hyperpigmentation, excessive hair growth on the face, and sometimes skin thickening and hair loss.

- Parakeratosis variegata - It's aetiology is unknown. It is characterised by ashy dermatosis - like eruption at the onset, which progressively involves the entire skin and turns gradually into poikiloderma (skin atrophy with speckle-like discolorations).

According to the work or task and doses of pesticides used in that task, risk and consequences differ, resulting in different symptoms. Therefore, the purpose of this research is to study and determine the prevalence of ophthalmological and dermatological problems related to Pesticide exposure among sugarcane farmers in western Maharashtra. Many studies have shown the problems associated to cardiovascular, respiratory, musculoskeletal systems but there is very less research done on the dermatological and ophthalmological problems related to pesticide exposure in western Maharashtra. Few studies have engrossed on the surveying of the general awareness of pesticide exposed 
farmers with respect to safety related preventive measures that need to be followed. So, there is necessity to analyse the prevalence of ophthalmological and dermatological problems related to pesticide exposure among sugarcane farm workers in western Maharashtra.

Key features of this study are dermatological and ophthalmological assessment protocol of above systems to assess various problems of pesticide exposed sugarcane farmers in western Maharashtra and determined the prevalence of skin and eye problems in pesticide exposed sugarcane farm workers.

\section{METHODS}

This observational study was carried out in some zones of western Maharashtra. Study duration was six months and was conducted from July 2020 to December 2020. Depending on the basis of inclusion (males 35 - 45 years old, Exposure more than 5 years.) and exclusion criteria (females, farmers with hypertension and any other metabolic diseases.) 79 farmers (sample size) were selected by the formula 4pq / $\mathrm{L}^{2}$ where, $\mathrm{p}=27.2, \mathrm{Q}=(100-\mathrm{P})=72.8$ and $\mathrm{L}=10$.

Written consent was taken from them. Participants were selected by random sampling method from 19 villages of western Maharashtra and their detailed outcome assessment was done by using dermatological assessment (assessment of skin) and ophthalmological assessment (assessment of eyes) protocol.

\section{Procedure}

Permission was taken from respective authorities. The procedure was started after the protocol and ethical clearance. The study was conducted in some areas of western Maharashtra, and the duration was 6 months. Depending on the base of inclusion (Males 35 - 45 years old, Exposure more than 5 years.) and exclusion criteria (females, farmers with hypertension and any other metabolic diseases.) 79 (sample size) farmers were selected by the formula $4 \mathrm{pq} / \mathrm{L}^{2}$ where, $\mathrm{P}$ $=27.2, \mathrm{Q}=(100-\mathrm{P})=72.8$ and $\mathrm{L}=10$ and written consent was taken from them. Participants were selected by random sampling method from some villages of western Maharashtra. Pesticide exposed sugarcane farmers were screened before selecting for the study and we described them about the procedure of the study.

Keeping all the above procedural criteria's in mind, we also collected the following demographic information (Name, Age, Occupation, Address, Dominant Side, Height, Weight, BMI, Socioeconomic status, Personal History and Date of assessment.) and assessment were taken by using dermatological and ophthalmological assessment protocol to rule out the problems of skin and eye. It includes farmers total physical examination and personal history.

\section{Subject Criteria}

In this study, total of 79 participants (farmers) having exposure to pesticides for more than 5 years were studied. Only male farm workers in the age group $35-45$ years old were selected for this study. Participants were selected randomly from the zones of western Maharashtra. Women (females were not included because most of the farm workers involved in pesticide spraying activities are male.) and agriculturalists with blood pressure related problems and other metabolic diseases such as diabetes were not involved in the study. Written informed consent was taken from the participants those who were ready to take part.

\section{RESULTS}

\begin{tabular}{|c|c|c|c|}
\hline Sl. No. & & Demographic Variables & No. of Participants (\%) \\
\hline \multirow{2}{*}{ I } & \multirow{2}{*}{ Age } & $35-45$ & No. of Participants (\%) \\
\hline & & $40-45$ & $43(54.43 \%)$ \\
\hline \multirow{3}{*}{\multicolumn{2}{|c|}{$\begin{array}{l}\text { II Type of } \\
\text { pesticide } \\
\text { exposures } \\
\text { 1.Plant growth } \\
\text { regulators }\end{array}$}} & $\begin{array}{l}\text { 2,4 - Dichlorophenoxyacetic } \\
\text { acid }\end{array}$ & $48(60.75 \%)$ \\
\hline & & $\alpha$ naphthalene acetic acid & $29(36.70 \%)$ \\
\hline & & Abscisic acid & $35(44.30 \%)$ \\
\hline \multirow{11}{*}{2} & \multirow{5}{*}{ Insecticides } & Organophosphates & $56(70.88 \%)$ \\
\hline & & Carbamates & \multirow{2}{*}{$\begin{array}{l}69(87.34 \%) \\
40(50.63 \%)\end{array}$} \\
\hline & & Acephate $75^{0}$ & \\
\hline & & Carbofuran 3G & $21(26.58 \%)$ \\
\hline & & $\begin{array}{l}\text { Chlorpyrifos } 50 \%+ \\
\text { Cypermethrin } 5 \% \text { EC }\end{array}$ & $63(79.74 \%)$ \\
\hline & \multirow{6}{*}{ 3.Fertilizers } & Carbamide $\left[\mathrm{CH}_{4} \mathrm{~N}_{2} \mathrm{O}\right]$ & $76(96.20 \%)$ \\
\hline & & NPK 15:15:15 & $50(63.29 \%)$ \\
\hline & & NPK 19:19:19 & $65(82.27 \%)$ \\
\hline & & NPK 18:46:0 & $40(53.63 \%)$ \\
\hline & & Muriate of potash [KCI] & $48(60.75 \%)$ \\
\hline & & Ammonium sulphate & $64(81.01 \%)$ \\
\hline \multirow{3}{*}{4} & \multirow{3}{*}{$\begin{array}{c}\text { Duration of } \\
\text { exposure [years] }\end{array}$} & $5-8$ & \multirow{3}{*}{$\begin{array}{l}14(17.72 \%) \\
28(35.44 \%) \\
37(46.83 \%)\end{array}$} \\
\hline & & $8-10$ & \\
\hline & & $\geq 10$ & \\
\hline \multirow{6}{*}{5} & \multirow{6}{*}{ PPE } & & Yes \\
\hline & & Ophthalmic: - Goggles & $60(75.94 \%) \quad 19(24.05 \%)$ \\
\hline & & Face shields & $1(1.26 \%) \quad 78(98.73 \%)$ \\
\hline & & $\begin{array}{l}\text { Dermatological: - mask / } \\
\text { scarf }\end{array}$ & $65(82.27 \%) \quad 14(17.72 \%)$ \\
\hline & & Gloves & $43(54.43 \%) \quad 36(45.56 \%)$ \\
\hline & & Proper clothing & $67(84.81 \%) \quad 12(15.18 \%)$ \\
\hline \multicolumn{4}{|c|}{ Table 1. Demographic Variables } \\
\hline
\end{tabular}

\begin{tabular}{|ccc|}
\hline Ophthalmological Problems & $\begin{array}{c}\text { Present } \\
\text { No of subjects } \\
\text { (Percentages) }\end{array}$ & $\begin{array}{c}\text { Absent } \\
\text { No of Subjects } \\
\text { (Percentages) }\end{array}$ \\
\hline Irritation & $51(64.5 \%)$ & $28(35.4 \%)$ \\
Burning sensation & $48(60.7 \%)$ & $31(39.2 \%)$ \\
Itching & $43(54.4 \%)$ & $36(45.5 \%)$ \\
Blurring of vision & $17(21.5 \%)$ & $62(78.4 \%)$ \\
Watering of eyes & $35(44.3 \%)$ & $44(55.6 \%)$ \\
Cataract & $2(2.5 \%)$ & $77(97.4 \%)$ \\
Conjunctivitis & $10(12.6 \%)$ & $69(87.3 \%)$ \\
\hline \multicolumn{3}{r}{ Table 2. Ophthalmological Problems } \\
\hline \multicolumn{3}{|c}{} \\
\hline
\end{tabular}

\section{Interpretation}

Out of total $79(100 \%)$ sample size, most common problems were the irritation [51 (64.5\%)], burning sensation [48 (60.7 $\%)$ ], itching [43 (54.4\%)], and watering of eyes [35 (44.3\%)] and the less common problems due to pesticide exposure were the blurring of vision [17 $(21,5 \%)]$, cataract [2 (2.5\%)] and, conjunctivitis [10 (12.6\%)].

\begin{tabular}{|ccc|}
\hline $\begin{array}{c}\text { Dermatological } \\
\text { Problems }\end{array}$ & $\begin{array}{c}\text { Present } \\
\text { No. of Subjects } \\
\text { (Percentages) }\end{array}$ & $\begin{array}{c}\text { Absent } \\
\text { No. of Subjects } \\
\text { (Percentages) }\end{array}$ \\
Contact dermatitis & $29(36.7 \%)$ & $50(63.2 \%)$ \\
Urticaria & $13(16.4 \%)$ & $66(83.5 \%)$ \\
Ashy dermatosis & $5(6.32 \%)$ & $74(93.6 \%)$ \\
Itching & $46(58.2 \%)$ & $33(41.7 \%)$ \\
Hypopigmentation & $1(1.26 \%)$ & $78(98.7 \%)$ \\
Dehydrated skin & $51(64.55 \%)$ & $28(35.4 \%)$ \\
Nail dystrophy & $0(0 \%)$ & $79(100 \%)$ \\
Skin cancer & $0(0 \%)$ & $79(100 \%)$ \\
Erythema multiforme & $9(11.3 \%)$ & $70(88.6 \%)$ \\
\hline \multicolumn{2}{|c|}{ Table 3. Dermatological Problems } \\
\hline \multicolumn{3}{|c}{} \\
\hline \multicolumn{2}{|c}{} \\
\hline
\end{tabular}




\section{Interpretation}

Some problems in dermatological system related to pesticide exposure such as contact dermatitis [ (29 (36.70 \%)]. People of the sample size [79 (100\%)], urticarial [13 (16.4\%)], ashy dermatosis [5 (6.32 \%)], itching [46 (58.22 \%)], hypopigmentation [1 (1.26 \%)], nail dystrophy [0 (0 \%)], skin cancer [0 (0 \%)] erythema multiforme [9 (11.39\%)] and people who were found to be dehydrated were [51 (64.55 $\%)]$. Out of above problems, itching (46 subjects) and dehydrated skin (51 subjects) were the most common problems.

\section{Statistical Analysis}

At the baseline, the outcome measures were evaluated. The collected data in this study was statistically analysed using graphic statistics as bar graph and percentages. For both dermatological and ophthalmological problems, bar graph were used. Final results were considered in the form of percentages (\%).

\section{DISCUSSION}

Pesticide exposed agriculturalists are at higher risk of health problems due to excessive use of pesticides and improper use or illiteracy of practice of protective measures such as gloves, masks, appropriate clothing etc. Such improper use of pesticides may have detrimental effects on health of farmers. It may affect several systems of the body (central nervous systems, gastrointestinal, respiratory, also the ophthalmic and dermatological symptoms etc.) This study "ophthalmological and dermatological problems related to pesticide exposure" was conducted to assess the prevalence of ophthalmological and dermatological problems in pesticide exposed farmers. ${ }^{2,4}$

A systemic review related to dermatological system, the author Spiewak R: Pesticides as a cause of occupational skin diseases in farmers. Ann Agric Environ Med 2001, 8,1-5 found similar results. The result in this study were contact dermatitis, both allergic or irritants were the most pesticide related dermatoses. Urticaria, porphyria cutanea tarda, hypopigmentation of skin, nail and hair disorders are the possible rare clinical forms. Both arsenic and non-arsenic pesticides are potentially carcinogenic, in that arsenic pesticides exposed farmers are at risk of occupational skin cancer, squamous cell carcinoma.

Also, in similar study related to ocular problems named Jaga K, Dharmani C., Ocular toxicity from pesticide exposure: A recent review. Environmental health and preventive medicine. 2006 May 1;11(3):102 - 7 stated similar findings most commonly described effects of pesticides on eyes are irritation, itchiness, watering of eyes, and blurring of vision. Retinal degeneration is also possible due chronic exposure of pesticides. Objectives of eye care is the safety of eyes, protection of vision, and maintaining good eye health. - $^{4}$

One study from same region highlights the prevalence of impairments in pulmonary function test (PFT) in sugar distillery industry workers ${ }^{27}$ and therapeutic aspect for occupational problems such as occupational load specific exercise protocol on cumulative trauma disorder of upper limb in construction workers is also very much important. ${ }^{28}$ Impact of common skin problems such as pressure ulcers on therapeutic outcomes. ${ }^{29}$ Oedematous conditions of lower limb are one of the reason of compressive neuropathy. ${ }^{30}$

Above findings majorly correlate with the findings of the current study adding to the efficacy of results obtained. There is important need for developing awareness and education about pesticide exposure in order to sustain community and public eye and skin health. In this study, we assessed the farmers for dermatological and ophthalmological conditions by using appropriate assessment protocols.

The results of this present study showed that, there is significant problems in ophthalmological system which is irritation in eyes, burning sensation, itching, blurring of vision, watering of eyes, cataract and conjunctivitis. Out of above problems, irritation in eyes, burning sensation and itching are the most common problems whereas cataract and conjunctivitis are the least common problems. It also shows significant problems in dermatological system such as contact dermatitis, urticaria, ashy dermatosis, itching hypopigmentation, dehydrated skin, nail dystrophy, skin cancer and erythema multiforme. Out of above problems, itching and dehydrated skin are the most common problems whereas skin cancer, hypopigmentation and nail dystrophy are the least common problems.

Clinical significance of this study is that the sugarcane farmers have the uppermost risk of work-related hazards because of improper methods of handling pesticides and it may lead to numerous impairments. This pesticidal impairments such as pain, visual impairments, blurring of vision, dehydrated skin, itching and irritation of both eyes and skin etc. may lead to further complications such as cataract, conjunctivitis, blindness, skin cancer etc., so more attention towards preventive steps and creating awareness is necessary.

Application of work section is to create the awareness among farmers about impairments, dermatological and ophthalmological associated conditions which will happen in future and to predict its effects on quality of life so that we can provide advices for education and prevention.

Certain policies provided by government like "The world bank policy on pest management (OP 4.09)" which promotes use of biological or environmental control methods and reduces reliance on chemical pesticides and "Integrated pest management plan (IPMP)" focuses on issues of excessive use of chemical pesticides in agriculture. ${ }^{31}$ We can also recommend some policies regarding strict compulsion of using protective equipment in rural areas to make them aware about it.

\section{CONCLUSIONS}

On the basis of results, it was concluded that large number of pesticide exposed sugarcane farm workers were exposed to various impairments with varying levels of vulnerability. Both, ophthalmological and dermatological systems are vulnerable. Prevalence of ophthalmological and dermatological problems were $37.2 \%$ and $21.6 \%$ respectively. By assessment of the ophthalmological and dermatological systems (assessments of eyes and skin), it 
was concluded that there are significant problems in both ophthalmological system and dermatological system. Ophthalmological problems include irritation, burning sensation, itching, blurring of vision, watering of eyes, cataract and conjunctivitis. Dermatological problems include contact dermatitis, urticaria, ashy dermatosis, itching, hypopigmentation, dehydrated skin, nail dystrophy, skin cancer, and erythema multiforme.

Data sharing statement provided by the authors is available with the full text of this article at jemds.com.

Financial or other competing interests: All authors received grants from Krishna Institute of Medical Sciences Deemed to Be University, Karad, Maharashtra.

Disclosure forms provided by the authors are available with the full text of this article at jemds.com.

\section{REFERENCES}

[1] Patil DA, Katti RJ. Modern agriculture, pesticides and human health: a case of agricultural labourers in Western Maharashtra. Journal of Rural Development 2012;31(3):305-18.

[2] Kori RK, Thakur RS, Kumar R, et al. Assessment of adverse health effects among chronic pesticide-exposed farm workers in Sagar District of Madhya Pradesh, India. International Journal of Nutrition, Pharmacology, Neurological Diseases 2018;8(4):153.

[3] Spiewak R. Pesticides as a cause occupational skin diseases in farmers. Ann Agric Environ Med 2001;8(1):15.

[4] Jaga K, Dharmani C. Ocular toxicity from pesticide exposure: a recent review. Environ Health Prev Med 2006;11(3):102-7.

[5] Li Y, Zhang C, Yin Y, et al. Neurological effects of pesticide use among farmers in China. Int J Environ Res Public Health 2014;11(4):3995-4006.

[6] Kirkhorn SR, Schenker MB. Current health effects of agricultural work: respiratory disease, cancer, reproductive effects, musculoskeletal injuries and pesticide-related illnesses. J Agric Saf Health 2002;8(2):199-214.

[7] Sapbamrer R, Nata S. Health symptoms related to pesticide exposure and agricultural tasks among rice farmers from northern Thailand. Environ Health Prev Med 2014;19(1):12-20.

[8] Centers for Disease Control and Prevention (CDC). Illness associated with drift of chloropicrin soil fumigants into a residential area--Kern country, California, 2003. MMWR Morb Mortal Wkly Rep 2004;53(32):740-2.

[9] Echobichon DJ. Toxic effects of pesticide. In: Klassen CD, Doull J, eds. Cassarett and Doull's Toxicology. NewYork: McGraw-Hill 1996:643-89.

[10] Sullivan JB Jr, Blose J. Organophosphate and carbamate insecticide. In: Sullivan JB, Krieger GR, eds. Hazardous Materials Toxicology: Clinical Principles of Environmental Health. Baltimore, Maryland: Williams and Wilkins 1992:1015-26.

[11] Bradberry SM, Proudfoot AT, Vale JA. Glycophosphate poisoning. Toxicol Rev 2004;23(3):159-67.
[12] Centers for Disease Control (CDC). Update: hydrogen cyanamide-related illnesses-Italy, 2002-2004. MMWR Morb Mortal Wkly Rep 2005;54(16):405-8.

[13] Gomes J, Lloyd O, Revitt MD, et al. Morbidity among farm workers in a desert country in relation to long-term exposure to pesticides. Scand J Work Environ Health 1998;24(3):213-9.

[14] Lu JL. Risk factors to pesticide exposure and associated health symptoms among cut-flower farmers. Int J Environ Health Res 2005;15(3):161-9.

[15] Strong LL, Thompson B, Coronado GD, et al. Health symptoms and exposure to organophosphate pesticides in farmworkers. Am J Ind Med 2004;46(5):599-606.

[16] Schenker MB, Albertson TE, Saiki CI. Pesticides. In: Rom WN, ed. Environmental and Occupational Medicine. Toronto, London: Little Brown and Company 1992:887920.

[17] Wolfe HR, Armstrong JF, Durham WF. Pesticide exposure from concentrate spraying. Arch Environ Health 1966;13(3):340-4.

[18] Brown R. Contac sensitivity to diflolatan (Captafol). Contact Dermatitis 1984;10(3):181-2.

[19] Camarasa G. Diflolatan dermatitis. Contact Dermatitis 1975;1(2):127.

[20] Lisi P, Caraffini S, Assalve D. Irritation and sensitization potential of pesticides. Contact Dermatitis 1987;17(4):212-8.

[21] Peluso AM, Tardio M, Adamo F, et al. Multiple sensitization due to bis-dithiocarbamate and thiophthalimide pesticides. Contact Dermatitis 1991;25(5):327.

[22] Sharma VK, Kaur S. Contact sensitization by pesticides in farmers. Contact Dermatitis 1990;23(2):77-80.

[23] Li WM. The role of pesticides in skin disease. Int J Dermatol 1986;25(5):295-7.

[24] McCord CP, Kilkee CH. Pyrethrum dermatitis. J Am Med Assoc 1921;77(6):448-9.

[25] Hindson C, Diffey B. Phototoxicity of glyphosate in a weed killer. Contact Dermatitis 1984;10(1):51-2.

[26] Savitt LE. Contact dermatitis due to benomyl insecticide. Arch Dermatol 1972;105(6):926-7.

[27] Pawar PM, Shinde SB. Prevalence of impairment in pulmonary function test in sugar distillery industry workers in karad taluka. Asian Journal of Pharmaceutical and Clinical Research 2019;12(2):428-31.

[28] Kulkarni M, Shinde SB. Effect of occupational load specific exercise protocol on cumulative trauma disorder of upper limb in construction workers. Journal of Evolution of Medical and Dental Sciences 2020;9(20):1599-604.

[29] Shinde SB, Varadharajulu G. Impact of pressure ulcers on therapeutic outcomes in inpatient physiotherapy services. Journal of Evolution of Medical and Dental Sciences 2020;9(31):2187-91.

[30] Jaju CS, Shinde S. Prevalence of peripheral neuropathy in chronic musculoskeletal oedematous conditions. International Journal of Physiotherapy 2019;6(6):282-6.

[31] Mukul MR. Bangladesh-South Asia-P161996-Sustainable Forests and Livelihoods (SUFAL) project-procurement plan. The World Bank 2020. 